\title{
UMA PENA FEMININA EM COMBATE: A EXPRESSÃO LTTERÁRIA E EDUCATIVA DE CARMEN DOLORES NAS CRÔNICAS DE O PAIZ (1905-1910)
}

\author{
A FEMININE PEN IN COMBAT: THE LITERARY AND \\ EDUCATIONAL EXPRESSION OF CARMEN \\ DOLORES IN THE CHRONICLES OF "O PAIZ"
}

(1905-1910)

\author{
ANA MARIA BANDEIRA DE MELLO MAGALDI(D)
}

\section{Resumo}

No presente artigo, a intenção é de lançar luz sobre a expressão literária e educativa de Carmen Dolores, pseudônimo de Emília Moncorvo Bandeira de Mello (1852-1910), escritora e intelectual de grande prestígio no mundo das letras do Rio de Janeiro e do país, na virada do século XIX para o XX. Reconhecida como autora de obras de gêneros diversos, notabilizou-se por seu talento como cronista, que desenvolveu em diversos veículos da imprensa de então. O foco do estudo, que dialoga com o campo da história cultural, estará dirigido à sua colaboração em $O$ Paiz, considerado um dos principais jornais brasileiros da época, no período de 1905 a 1910, quando, através de suas crônicas, destacou-se pela firmeza de opiniões e combatividade no enfrentamento dos temas abordados. De modo particular, será conferida atenção aos embates em que se envolveu, por meio de seus escritos, em torno de questões de grande relevo para o universo feminino, entre as quais se inscreveram as lutas de escritoras e intelectuais por afirmação em um cenário das letras eminentemente masculino. Também outras problemáticas cruciais vividas por mulheres de seu tempo, em um sentido mais amplo, foram alvo de sua pena, que se mobilizou fortemente em defesa da educação e do

\footnotetext{
a Universidade do Estado do Rio de Janeiro (UERJ), Rio de Janeiro, RJ, Brasil. Doutora em História, e-mail: anamagaldi29@gmail.com

Rev. Caminhos da Educação: diálogos, culturas e diversidades, Teresina, v. 2, n. 3, p. 10-37, set./dez. 2020
} 
trabalho femininos, do divórcio, entre outras pautas, dialogando com o movimento feminista daquele momento, e assumindo importante dimensão educativa.

Palavras-chave: Carmen Dolores; História da educação brasileira; Mulheres de letras; Educação feminina; Feminismo..

\section{Abstract}

The present article's intention is to cast light on the literary and educational expression of Carmen Dolores, pseudonym of Emilia Moncorvo Bandeira de Mello (1852-1910), prestigious author and intellectual in the literary world of Rio de Janeiro and Brazil at the turn of the nineteenth century. Recognized as author of diverse literary genres, she gained distinction for her talent as a chronicler, who flourished in several printed vehicles at the time. The focus of this study, which dialogues with the field of cultural history, is directed at her collaboration in "O Paiz", considered one of the principal Brazilian journals of the time in the period 1905-1910. Through her chronicles, she stood out for her firm opinions and combativeness in touching on issues of the time. Particularly, attention will be given to the discussions touched upon in her writings on themes of great relevance to the feminine universe, among which was the struggle of female writers and intellectuals in the face of an eminently masculine world of letters. Also, other crucial problems were the target of her pen, experienced by women of her time in a more ample sense, which strongly mobilized in defense of education, of feminine works and of divorce, among others issues, dialoguing with the feminist movement of the time and assuming a significant educational dimension.

Keywords: Carmen Dolores; History of Brazilian education; Literary women; Feminine education; Feminism.

\section{Resumen}

La intención de este artículo es arrojar luz sobre la expresión literaria y educativa de Carmen Dolores, seudónimo de Emilia Moncorvo Bandeira de Mello (1852-1910), escritora e intelectual de gran prestigio en el mundo de las letras de Río de Janeiro y del país en el paso del siglo XIX al XX. Reconocida como autora de obras de distintos géneros, sobresalió por su talento como cronista, labor que desarrolló en diversos medios de la prensa de la época. El estudio, que dialoga con el campo de la historia cultural, se centrará en su colaboración en O Paiz, considerado uno de los principales periódicos brasileños de la época, en el período de 1905 a 1910, cuando a través de sus crónicas se destacó por su firmeza de opinión y la combatividad en enfrentar los temas abordados. En particular, se le dará atención a los enfrentamientos en los que se involucró por medio de sus escritos en torno a temas de gran relevancia para el universo femenino, entre los que se encontraban las luchas de escritoras e intelectuales por afirmación en un escenario de las letras que era eminentemente masculino. Asimismo, 
otras problemáticas cruciales vividas por las mujeres de su tiempo, en un sentido más amplio, fueron objeto de su pluma, que se movilizó fuertemente en defensa de la educación y el trabajo de las mujeres, el divorcio, entre otras pautas, en diálogo con el movimiento feminista de la época y asumiendo una importante dimensión educativa.

Palabras clave: Carmen Dolores; Historia de la educación brasileña; Mujeres de letras; Educación femenina; Feminismo.

Carmen Dolores era lida no país inteiro, a princípio com a curiosidade que inspirava um nome singular e um nome de mulher. Depois, com interesse; depois ainda, com devoção, que de muitos sei a quem as suas crônicas eram o pábulo semanal para as delícias do espirito.

Júlio Porto-Carrero

Ela se manifestou sempre e com estrondo. Fez da pena de cronista uma arma de combate e por isto foi lida, discutida aclamada e derredor do seu nome criou-se esta permanência de interesse (...). A sua figura teve no meio uma bravura de rebelião que diz, pelo arrojo fenomenal que representa, com a fase de reinvindicação em que a mulher aparece diante do homem gritando os seus direitos e as suas aspirações aos mesmos domínios e aos mesmos gozos.

Gilberto Amado

Carmen Dolores, pseudônimo de Emília Moncorvo Bandeira de Mello (18521910), foi uma escritora que conheceu grande prestígio na cena literária do Rio de Janeiro e do país, na virada do século XIX para o XX. Autora de obras de gêneros diversos, notabilizou-se pela personalidade e pela firmeza de suas opiniões, manifestadas em crônicas publicadas em jornais cariocas. ${ }^{1}$ Nesse estudo, o foco estará dirigido para sua colaboração no diário O Paiæ, editado na Capital da República e apresentado aos leitores como "o jornal de maior tiragem e de maior circulação da

\footnotetext{
${ }^{1}$ Há registros de sua colaboração em O Paiz, Correio da Manhã, A Imprensa e L'Étoile du Sud, periódico francês publicado no Rio de Janeiro. Em sua carreira literária, destacou-se, ainda, como autora de contos, de um romance e de uma peça teatral.

Rev. Caminhos da Educação: diálogos, culturas e diversidades, Teresina, v. 2, n. 3, p. 10-37, set./dez. 2020
} 
América Latina"2, atuando como cronista no período que se estende de 1905 até sua morte, em 1910. Suas crônicas eram publicadas aos domingos, ocupando um espaço de destaque e visibilidade, na primeira página, no canto esquerdo e no alto da mesma, localização que poderia sugerir uma porta de entrada para a leitura do jornal, no dia mais valorizado da semana, em que havia expectativa de um número maior de leitores. Há evidências de que era muito lida no país, de ter conhecido um grande sucesso de público e de crítica com esses seus textos dominicais, como indicam o médico Júlio Porto-Carrero e o jornalista Gilberto Amado, que a substituiu na coluna em O Paiz, em artigos publicados em homenagem à cronista, após seu falecimento.

Como inúmeros estudos já têm assinalado, a notoriedade no mundo das letras e na vida pública de um modo geral não representou uma marca comum na vida de mulheres, naquele contexto do alvorecer do século XX. Em realidade, muito poucas figuras do sexo feminino puderam encontrar reconhecimento nos meios letrados da Belle Époque carioca, ainda que esse status não tivesse levado à fixação de seus nomes na memória literária brasileira de modo equivalente aos dos homens. Prestígio semelhante, talvez somente Júlia Lopes de Almeida tenha conhecido então, tendo, inclusive, ocupado um lugar como cronista no mesmo jornal O Paiz, às terças-feiras. Carmen Dolores, foi, assim, uma das importantes exceções, cujo estudo apresenta plena justificação, pelo impacto que suas palavras e ideias produziram em seu tempo.

A compreensão sobre a importância dessa escritora tem-se afirmado em tempos recentes, principalmente no campo dos estudos literários, mas também nos meios historiográficos ${ }^{3}$, observando-se um particular interesse por sua figura no caso de pesquisas focadas no tema do feminismo, ou dotadas de abordagem feminista. $\mathrm{Na}$ esteira dessa tendência, que vem adquirindo maior força nas últimas décadas, diferentes investigações têm contribuído para enfrentar e superar um silenciamento injustificável que havia perdurado, por muito tempo, sobre sua trajetória intelectual e sua produção. A intenção desse estudo é de concorrer nessa direção, procurando

\footnotetext{
${ }^{2}$ Considerando o período focalizado no estudo, a apresentação do jornal dessa forma é observada pelo menos desde o início de 1905 até 15/05/1907. A partir de 16/05/1907, e até o final de 1910, O Paiz é apresentado como "Jornal independente, político, literário e noticioso."

${ }^{3}$ Entre os trabalhos historiográficos, situam-se os de SOIHET (2004) e SOIHET; ESTEVES (2008) e, em meio aos estudos literários, pode ser destacado o de HELLMANN (2015).

Rev. Caminhos da Educação: diálogos, culturas e diversidades, Teresina, v. 2, n. 3, p. 10-37, set./dez. 2020
} 
também valorizar a dimensão educativa de sua obra, assim como a presença da temática educacional na mesma, focalizando as crônicas semanais que publicou em $O$ Paiz, em um cenário de profundas transformações vividas na sociedade brasileira e, de modo singular, no Rio de Janeiro, em múltiplos sentidos. ${ }^{4}$

Nas colunas de Carmen Dolores, eram focalizados assuntos muito diversos sobre a vida na cidade, profundamente modificada em um quadro de modernização intensa de sua estrutura urbana e de sua dinâmica cultural e social. Um exemplo interessante da expressão da autora como participante e observadora do cotidiano da cidade e das transformações em curso, envolveu uma crônica em que narrava o dia da importante inauguração da Avenida Central, em 15 de novembro de 1905, mencionando o fato de as festividades dedicadas ao progresso materializado no cenário urbano terem sido sucedidas por uma chuva torrencial e por uma enchente de proporções impressionantes. Em seu texto, a cronista dá destaque às águas sujas borrando o esplendor da festa e trazendo grandes incômodos à população presente no centro da cidade para celebrar a modernidade representada pela larga avenida construída à imagem dos bulevares parisienses e inaugurada, não à toa, na data em que se comemorava a adoção do regime republicano, identificado ao progresso pelas elites dirigentes do país. As enchentes, já muito conhecidas da população que habitava a cidade localizada à beira mar, cortada por rios e desprovida de uma estrutura de escoamento apropriada, foram assunto de vários outros textos seus, mostrando que a vivência de alagamentos era rotineira, o que, como hoje se sabe, continuaria a sê-lo por décadas e mesmo por mais de um século à frente.

Com humor crítico e irônico, tom recorrente em seus textos, a autora dava seu testemunho sobre aquele dia festivo, enfatizando a presença indesejável do antigo problema estrutural da cidade:

Enquanto se inaugurava a grande Avenida, no dia 15, as ruas enchiam, e quando começou a afluir gente de torna-viagem, cansada de tanto esplendor e levemente embrutecida por tanta novidade e tanta água a um só tempo, os bondes já nadavam sobre ondas revoltas cor de barro e os animais afundavam meia perna e afinal a perna inteira. (...). O Mangue apresentava altivamente uma superfície de oceano.

\footnotetext{
${ }^{4}$ Sobre a riqueza das crônicas como fontes documentais em estudos historiográficos, ver CHALHOUB, NEVES e PEREIRA, 2005.

Rev. Caminhos da Educação: diálogos, culturas e diversidades, Teresina, v. 2, n. 3, p. 10-37, set./dez. 2020
} 
Continuando a narrativa, a cronista relatou a cena emblemática de um "distinto cavalheiro" vindo "da festa, acartolado, soberbo, mas já molhado como um pinto" e que, ao saltar do bonde, parecia "um náufrago" cujas "mãos enluvadas faziam o gesto dos nadadores, afastando as ondas diante de si...", naquele dia em que se exaltava o "triunfo da civilização e do progresso" na "cidade embandeirada e jubilosa". (DOLORES, 19/11/1905, p.1)

No espaço intitulado $A$ Semana, dividido, com frequência, em duas ou três partes, eram abordados, a cada domingo, assuntos diferentes, de maneiras também diversas. Nos escritos de Carmen Dolores, em que independência de opinião, rigor e erudição na exploração do tema eram marcas habituais, seriam observados também traços, comumente combinados em variados tons, como humor, ironia, seriedade e aspereza, dependendo do objeto a que dirigia seu olhar crítico. O interesse da escritora, em sua observação e análise da realidade, poderia se encaminhar tanto para acontecimentos pontuais do cotidiano da cena urbana na semana anterior, quanto para questões complexas que mobilizavam debates nos meios intelectuais da época, tratadas com a densidade requerida.

Entre os assuntos da vida da cidade que mobilizavam a atenção da cronista, incluíam-se problemas climáticos e os transtornos produzidos pelos mesmos, sendo focalizadas as altas temperaturas observadas no verão, gerando temporais, como o do dia da inauguração da Avenida Central, assim como o hábito, compartilhado pelas elites cariocas às quais pertencia, de subir a serra para fugir de incômodos como esses. Questões sociais diversas também estiveram na mira de sua pena, tratadas, por exemplo, através do foco no funcionamento dos bondes, em problemas habitacionais que atingiam setores populares, entre outros assuntos, em crônicas em que se observa, com frequência, um tom de denúncia dirigido a situações vistas como de injustiça. Intervenções urbanísticas então em curso na Capital da República, como a mencionada abertura da Avenida Central, foram, do mesmo modo, alvo da pena crítica de Carmen Dolores.

As crônicas publicadas em O Paiz abordavam, ainda, acidentes, tragédias, crimes - passionais, de modo geral, e tendo mulheres, como alvos principais -, Rev. Caminhos da Educação: diálogos, culturas e diversidades, Teresina, v. 2, n. 3, p. 10-37, set./dez. 2020 
suicídios, entre outros fatos que tivessem chocado a população. A autora comentava, além disso, matérias diversas publicadas nas páginas dos jornais ao longo da semana anterior, explorando ocorrências de impacto vividas também em outros países. Situações relativas ao cotidiano da cidade de Petrópolis, aonde se refugiava, ao lado de muitas famílias das classes favorecidas, eram trazidas aos leitores e leitoras, durante suas temporadas na serra fluminense.

Se a vida política costumava ser um assunto explorado com destaque nas páginas dos veículos da imprensa de modo geral, não atraía o interesse de Carmen Dolores, de modo particular. Quando fazia referência ao tema, sublinhava explicitamente que procurava evitá-lo, como no trecho em que se perguntava: "Que dizer mais (...) quando só algumas linhas em branco me restam na limitada coluna? Falar de política? Não, já me desinteressei." (DOLORES, 06/06/1909, p.1) Nos poucos momentos em que a escritora focalizava o assunto, o fazia mostrando uma profunda desconfiança em relação à atividade política, em especial na forma como se expressava naqueles primeiros tempos republicanos. Assumidamente monarquista e simpatizante de D. Pedro II, apontava, como outros contemporâneos seus, para a degradação da cena política, associando-a à adoção do novo regime, tema que foi objeto de importantes estudos historiográficos, como de Nicolau Sevcenko (1999). Marcava claramente seu ponto de vista: "E quanto à política atual, abomino-a." (DOLORES, 19/06/1910, p.1)

Ao contrário da política, o panorama literário, artístico e cultural da cidade representou um objeto de atenção privilegiado pela autora, que opinava sobre peças teatrais, espetáculos musicais, livros recém publicados, ou a ela enviados por autores desejosos de seu parecer, conferências literárias, entre outros eventos. Cenas da vida europeia, e principalmente, francesa, no campo das artes e das letras, também eram analisadas com destaque em suas crônicas.

As conferências literárias representaram uma forma de expressão de prestígio indiscutível nos meios letrados cariocas à época e, entre aquelas comentadas com maior interesse em $A$ Semana, esteve a proferida por Júlia Lopes de Almeida, na tarde de sábado, 18 de novembro de 1905, celebrada por Carmen Dolores na coluna publicada no dia seguinte:

Rev. Caminhos da Educação: diálogos, culturas e diversidades, Teresina, v. 2, n. 3, p. 10-37, set./dez. 2020 
É hoje, sábado, que a Sra. D. Júlia Lopes de Almeida realiza a sua conferência sobre o império da moda, que pretendo ouvir e aplaudir conscienciosamente por dois fortes motivos: $1^{\circ}$, porque a preleção há de ser realmente bela e digna do talento de quem a faz; $2^{\circ}$, porque essa distinta senhora quebra a rotina e apresenta-se valentemente numa tribuna até aqui só ocupada por homens. É um triunfo sobre o preconceito que merece calorosas palmas. (DOLORES, 19/11/1905, p.1, grifo da autora $)^{5}$

\section{Uma "pena de mulher" entre dores e lutas}

Apesar do comentário sobre o preconceito de que eram alvo mulheres intelectuais, ao focalizar a conferência de Júlia Lopes de Almeida, Carmen Dolores não se apresentava como uma voz feminina, em sua particularidade de gênero. Em uma de suas crônicas, assinalava:

Devo dizer que o que mais aprecio na literatura feminina é a insexualidade espiritual da escritora, cronista ou romancista, porquanto a arte veste uma chlamyde luminosa sem distinções de sexo que o olhar da crítica não tem o direito de traspassar. Não entendo essa coisa de escrever como um homem ou como uma mulher: deve se escrever simplesmente como artista, obedecendo livremente à sua visão própria, ao seu temperamento, à sua maneira de sentir." (DOLORES, 06/09/1908, p.1).

Posicionando-se contra a consolidação de um "círculo de eleitos" no mundo das letras, vista como injusta, em geral, defendia que esse espaço se constituísse em um "campo aberto a todo e qualquer concorrente de valor!". E enfatizava: "Salientese, reconheça-se e aplauda-se o talento, seja quem for aquele que o assinale em trabalhos de merecimento." Nessa mesma crônica, em que focalizava o panorama literário francês e parisiense em contraste com o nosso, amparava-se na língua francesa para defender seu ponto de vista: "Em França, a palavra autor não tem feminino, e diz-se: a mulher-autor, o que prova que o talento não tem sexo, mas tem asas (...)” (DOLORES, 03/06/1906, p.2, grifo da autora)

\footnotetext{
${ }^{5}$ Mais tarde, em julho de 1907, Carmen Dolores também proferiria uma conferência, intitulada "A sociedade", no Instituto Nacional de Música, espaço que habitualmente sediava esse tipo de evento. Rev. Caminhos da Educação: diálogos, culturas e diversidades, Teresina, v. 2, n. 3, p. 10-37, set./dez. 2020
} 
Não obstante a defesa da expressão literária sem distinção de sexo, entendo que a marca feminina representa um elemento de grande importância nos escritos de Carmen Dolores. A negação desse traço parecia estar associada à afirmação de seu distanciamento em relação a um modelo de mulher passivo e subalternizado, comumente disseminado, em seu tempo, inclusive nos meios letrados, o que pode ser percebido nessa reflexão:

O meu espírito é inteiramente independente, oh! se o é!...e juro que o será sempre. Como senhora, pareço tímida e sorrio com gentileza a tudo, mas como escritora o caso é outro, tenho a minha consciência e só digo o que penso, o que quero e o que entendo. Mais depressa quebrarei a pena que me fornece o pão, do que a molharei jamais em água com açúcar para angariar simpatias e adesões, festinhas e elogios, mesmo proveitos materiais, das coteries convencionalistas, como arauto dos poderosos - que aliás não fazem mais do que pisar os desprotegidos, em cuja conta me tenho. (DOLORES, 13/12/1908, p.1, grifo da autora)

Ao reforçar o compromisso com a independência de suas ideias, Carmen Dolores procurava mostrar, como escritora, seu afastamento de características usualmente identificadas à condição feminina, apesar de indicar que as mesmas poderiam se manifestar no plano da convivência social. Parecendo habituada com um lugar de incômodo, a escritora apontava para um sentimento de desproteção que compartilhava no ambiente de disputa intelectual em que se encontrava imersa.

Em outra crônica, sublinhava o lugar ocupado por si mesma na cena cultural de seu tempo, ao estabelecer uma comparação com autores ${ }^{6}$ cujos textos "registraram impressões do cárcere e até da alcova”. Partindo dessa referência, refletia: “(...)logo eu, pequenino e obscuro espírito, posso bem fazer da minha torre dolorosa um palanque de onde observo, analiso e sorrio, comparo...” (DOLORES, 07/02/1909, p.1) Dessa torre de observação, se constituiria uma "visão própria" sobre a realidade, mencionada em trecho citado anteriormente (DOLORES, 06/09/1908, p.1), em que também sugeria que seu olhar, "seu temperamento" e "sua maneira de sentir" responderiam apenas à sua condição de artista, associada, na mesma reflexão, à “insexualidade espiritual". Mas a "visão própria” expressada pela cronista era a de

\footnotetext{
${ }^{6}$ Os autores em questão são Silvio Pellico e Xavier de Maistre.

Rev. Caminhos da Educação: diálogos, culturas e diversidades, Teresina, v. 2, n. 3, p. 10-37, set./dez. 2020
} 
uma mulher, na singularidade de sua trajetória como sujeito e como intelectual, com as marcas, dores e os constrangimentos sofridos em função de sua condição de gênero.

Se a autora enfatizava, em muitos de seus textos, a recusa a uma expressão feminina frágil e submissa, diferentes aspectos de sua experiência de escritora em um cenário intelectual eminentemente masculino, em que as interdições para uma mulher eram muito fortes e constantes, fomentaram suas reflexões dominicais. As tensões envolvidas nesse processo e a resistência diante de barreiras poderosas mostraram-se visíveis de forma repetida, sendo tratadas com profundidade em suas crônicas. Ainda que assinalasse, nos trechos destacados, as ideias de desproteção e de um lugar de dor a partir do qual enxergava o mundo, reforçava, por outro lado, na maior parte das vezes, a sua atitude de enfrentamento dessa situação adversa. Assim, a partir desse "palanque", que envolvia não apenas observação, mas intenso protagonismo, Carmen Dolores produzia e estimulava reflexões sobre ser uma mulher intelectual, naquele tempo.

É digno de nota que, embora tenha adotado, ao longo de sua trajetória intelectual, pseudônimos masculinos, provavelmente como recurso tático ${ }^{7}$ para 0 trânsito em um ambiente desfavorável, o nome com que ficou conhecida de seu público e lembrada após a sua morte foi feminino. Merece destaque ainda que, para além de lançar luz sobre questões que a mobilizavam, por seu percurso particular de mulher escritora, Carmen Dolores também tenha tratado, de forma recorrente em suas crônicas, de temas diversos de grande relevância para a vida feminina à época, em termos mais amplos.

Ainda sobre sua vivência no mundo das letras, um ponto bastante desenvolvido, em uma perspectiva crítica, envolveu a enorme diferença entre a forma como escritoras do sexo feminino eram consideradas no Brasil e em países europeus e, de modo especial, na França, cuja cultura representava uma referência essencial em sua trajetória intelectual. Assumindo seu pertencimento a um grupo de mulheres "que

\footnotetext{
${ }^{7}$ A compreensão sobre o viés tático de que se revestiu a atuação de Carmen Dolores, em diversos aspectos de sua luta pela afirmação de direitos das mulheres em um cenário de grandes resistências, dialoga com a perspectiva de Michel de Certeau sobre a dinâmica envolvendo estratégias e táticas em práticas cotidianas. CERTEAU, 1994, cap.3.

Rev. Caminhos da Educação: diálogos, culturas e diversidades, Teresina, v. 2, n. 3, p. 10-37, set./dez. 2020
} 
escrevemos, aqui no Brasil, e estamos marcadas pela imarcescível tara do livro, da pena e da tinta", Carmen Dolores denunciava o forte preconceito de que eram alvo, em nosso país. Entre as vozes representativas dessa discriminação, apontava a do escritor e jornalista Figueiredo Pimentel, que, expressando a visão de grande parte da sociedade, "não suporta a mulher que escreve", "abomina a mulher inteligente e de recursos cerebrais", preferindo "talvez passar a vida inteira com uma analfabeta serviçal a correr o medonho risco de passá-la com alguma bas-bleu (...)." (DOLORES, 31/07/1910, p.1, grifo da autora)

Em uma crônica em que se posicionava sobre o tema da educação feminina, estabelecia a comparação entre a situação da Europa, marcada pela "consagração gloriosa da mulher intelectual" e do Brasil, onde "o preconceito faz caretas imbecis de sistemático e ferrenho desdém, em frente à pena feminina que se esgrime valentemente pelo pão honesto.” (DOLORES, 08/04/1906, p.1). Esse “esgrimir", assinalado por Carmen Dolores e experimentado ao longo de sua vida, era reforçado em muitos de seus textos.

Respondendo a comentários habituais, comumente expressos como acusações, de que tanto sua figura, quanto sua escrita teriam uma marca "masculinizada", 8 dialogava com essa representação de uma maneira engenhosa e assertiva, apropriando-se da ideia preconceituosa veiculada a seu respeito, em seu favor. Mostrava associar a "masculinidade" ou "virilidade" - termos por vezes utilizados por si mesma - de sua pena, tanto à recusa quanto à produção de textos suaves ou "açucarados" comumente identificados à voz feminina e mais facilmente aceitáveis naquele ambiente, quanto à necessidade de mobilizar as armas possíveis para uma disputa conduzida em território adverso, em que a assimetria nos recursos de poder e a desvantagem experimentada por mulheres eram evidentes.

Assumia, assim, na cena literária, posições firmes e com frequência incômodas que, segundo suas palavras, seriam "próprias de uma espécie de tola intrépida como D. Quixote". (DOLORES, 07/02/1909, p.1) Identificando-se com o personagem,

\footnotetext{
${ }^{8}$ Ainda que calcada em preconceito e em estereótipos de gênero muito compartilhados então, a conotação atribuída a adjetivos como esse nem sempre era negativa. O escritor e crítico Agripino Grieco, por exemplo, elogiou na escritora "a independência de ideias, a virilidade fecunda e sã (...)". (18/08/1910)

Rev. Caminhos da Educação: diálogos, culturas e diversidades, Teresina, v. 2, n. 3, p. 10-37, set./dez. 2020
} 
convocava sua "obscura pena de tosca madeira" a atuar como sua "pobre lança quixotesca, para combatermos juntas alguns moinhos de vento”. (DOLORES, 15/04/1906, p.1) Em diversos textos, reforçou o combate em que se envolveu, inicialmente com poucos recursos, sem proteção, como chegou a refletir: “(...) a virilidade da pena não será talvez indispensável, como arma de defesa, à mulher que se atira sozinha às lutas literárias, sem padrinhos?” (DOLORES, 03/06/1906, p.2)

O enfrentamento permanente travado no campo das letras e da cultura era repetidamente apresentado a leitores e leitoras, como em uma crônica em que comentava a intensa oposição atraída para si, após se posicionar de maneira crítica sobre o tema da religião, por ela denunciada quando conduzida e experimentada em um viés obscurantista. Anunciava, então, sua firme posição: "Mas insultos não me movem, porque não me convencem. E se minha pena de mulher é uma acha ou pelo menos uma brasa - atiro-a sem medo à fogueira. É o meu protesto.” (DOLORES, 02/08/1908, p.1, grifo meu). Se aqui a ênfase é dirigida à marca de protesto presente em sua escrita - explicitamente apresentada como feminina, nesse texto -, em outra crônica, refletindo sobre "certa guerra injusta que me fazem em algumas rodas estabelecidas aqui", sugeria uma possível consequência: "alguma coisa se passa a propósito da minha individualidade literária que é talvez... é talvez uma vingança. Que importa? O mundo é largo e eu não mudo.” (DOLORES, 13/12/1908, p.1).

Ainda que seus textos sugerissem a vivência, no início de seu percurso como literata, de um sentimento doloroso de desconforto com a desvalorização por sua condição de mulher, Carmen Dolores sublinhava que essa situação teria se modificado, ao longo do tempo. Em sua última crônica, publicada apenas dois dias antes de seu falecimento, enfatizava a mudança de sua disposição no embate travado. Após apontar que João do Rio "achava graça em certas cóleras do princípio de minha carreira", respondia a essa impressão, dizendo: "hoje estou mais fria do que um pedaço do revestimento interno de um frigorífico da Nova Zelândia". Comentando a visão do mesmo escritor, com quem possuía familiaridade, dirigia-lhe uma observação crítica, ao narrar que ele lhe dava "conselhos com uma amabilidade que não excluía a ironia, como se me achasse mal preparada para a luta terrível das letras." (DOLORES, 14/08/1910, p.1) 
Apesar de a escritora se encontrar em um estado de extrema fragilidade física quando da publicação dessa coluna, motivado pela grave e longa enfermidade que encerraria sua vida apenas dois dias depois, parece ter desejado, mais uma e pela última vez, enfatizar sua resistência frente à marginalização, sugerindo experimentar um sentimento de vitória nesse final de sua carreira. Mesmo que, naquele momento dramático de sua vida, o vigor físico fosse algo completamente indisponível, talvez a reiteração de sua potência como mulher escritora, através do foco em sua frieza - ou dureza - diante de um ambiente hostil, obtida após um longo e sofrido aprendizado, pudesse representar, para além da importância para si mesma, um estímulo para a continuidade de uma luta que não teria fim após a sua morte, pois estava - como ainda está, no presente - longe de ser somente sua.

\section{Educação, trabalho, casamento, divórcio: em torno de um "triste destino feminino"}

Indo além do seu mundo particular, Carmen Dolores explorou em suas colunas questões de grande relevo para a vida de mulheres de seu tempo. Nesse panorama, a temática educacional foi objeto de diversas de suas crônicas, tendo como foco sua própria formação, ou sua visão sobre a educação feminina.

Sobre seu percurso formativo, enfatizava o contraste em relação a um modelo de educação tradicional, muito consolidado em nossa sociedade, apoiado em uma rígida diferenciação de gênero e voltado para a constituição de mulheres cuja atuação deveria se restringir ao universo privado, da casa, e que deveriam se manter passivas diante do lugar social inferior que lhes era atribuído. A religião católica, elemento central desse projeto educativo, constituiu-se em alvo importante de sua crítica, assim como os colégios confessionais comumente frequentados pelas moças das camadas favorecidas da sociedade.

$\mathrm{Na}$ reflexão sobre sua formação, bem distinta tanto da educação conventual, como da educação ornamental compartilhada por moças das elites brasileiras de seu 
tempo, a escritora sugeria a contribuição daquela sua experiência particular para o caminho trilhado no mundo das letras:

Que culpa tenho, afinal, se me não educaram pelas cartilhas dos conventos ou das instituições religiosas, aprendendo a preparar doces e biscoitos, nos primeiros e nas outras a fazer bem a reverência nos parloirs amáveis, a recitar fábulas em francês e a conhecer o exato valor da hipocrisia social e da reza nas capelas floridas, como governo da vida? Criada em uma escola prática, recebendo ensino forte dos conscienciosos homens do passado, quando Deus era ainda adorado sem os fanatismos piegas, excessivos, convencionais e ambiciosos do presente, é natural que me pareça perfeitamente justo usar da pena como uso. (DOLORES, 09/08/1908, p.1, grifo da autora)

A crítica aos fanatismos e hipocrisias associados à religião foi reforçada constantemente em suas colunas dominicais. Ainda que se apresentasse como católica praticante, acentuava sua adesão à mensagem cristã genuína, "de uma religião de paz e de amor" (DOLORES, 02/08/1908, p.1) cuja primeira base seria a igualdade, assim como sua crença em um "Deus que é grande, justo, bom, misericordioso", e cujo conforto espiritual estaria acessível tanto aos poderosos como aos humildes. (DOLORES, 04/06/1905, p.1) Recusava, por outro lado, uma "religião de ódio e domínio", em que "o clericalismo", a intolerância e a "carolice" tendiam a prevalecer (DOLORES, 02/08/1908, p.1), distanciando-se do "deus que forjam os interesses e as convenções do mundo atual" (DOLORES, 04/06/1905, p.1), e dos abusos e deturpações cometidos em nome do "verdadeiro Deus da justiça e da verdade". (DOLORES, 02/08/1908, p.1)

Em homenagem à escritora, após sua morte, Júlia Lopes de Almeida refletia sobre a consistência intelectual como marca do processo educacional vivido pela colega, assinalando a importância desse percurso para a constituição de um pensamento livre e crítico, expresso em sua escrita:

Com a sua ilustração, mais de uma vez Carmen Dolores nos afirmou nas suas crônicas ter estudado como um homem e com os melhores mestres de seu tempo, tendo concluído cedo os preparatórios que lhe dariam ingresso em qualquer de nossas escolas superiores, se a isso ela se tivesse proposto, ilustração aliás provada à saciedade nos seus escritos (...) (ALMEIDA, 23/08/1910, p.1) ${ }^{9}$

\footnotetext{
${ }^{9}$ Não foram obtidas informações precisas sobre a formação da escritora. A citação sugere a possibilidade de ter contado com mestres no espaço da casa, mas não fica claro se, durante algum momento de seu Rev. Caminhos da Educação: diálogos, culturas e diversidades, Teresina, v. 2, n. 3, p. 10-37, set./dez. 2020
} 
Se os exemplos dados sobre sua formação e seu lugar de destaque no mundo das letras da Capital da República já transmitiam a leitoras e leitores importantes mensagens acerca do tema, Carmen Dolores também produziu uma reflexão aprofundada sobre a educação feminina, em uma perspectiva mais ampla. Em uma de suas colunas, respondendo a uma consulta dirigida pelo jornal O Paiza seus leitores e leitoras, a escritora desenvolveu uma densa análise sobre a questão, partindo da exploração dos objetivos inscritos na pergunta "Como deve ser educada a mulher":

Trata-se de saber se devemos ser educadas para, pelo casamento, sermos sustentadas pelo homem, ou para nos tornarmos hábeis a prover a nossa própria subsistência pelo nosso único trabalho. Se admitis a primeira hipótese, em que consiste a educação feminina para o casamento? Se preferis a segunda, quais são os gêneros de trabalho em que a mulher pode, sem decair, ganhar a vida em nossa terra?

Segundo a escritora, o jornal pretendia estimular o debate sobre "o delicado e triste destino feminino que tudo ameaça e nada protege, nem sequer a lei, feita pelos homens." (DOLORES, 08/04/1906, p.1,grifo meu)

Em suas considerações sobre o tema, expressava um viés ao mesmo tempo realista e crítico. Associando a fina sensibilidade a uma abordagem racional e precisa sobre os dilemas que mulheres enfrentavam em suas vidas cotidianas, atentava para o peso representado pelas expectativas sociais a elas dirigidas:

Penso que - dadas as ardentes e legítimas aspirações de todos os pais brasileiros, que visam o casamento como fonte de respeitabilidade e base de apoio garantido para suas filhas, essas filhas não podem ir contra a corrente e têm de ser forçosamente educadas para o casamento. (DOLORES, 08/04/1906, p.1)

Segundo suas palavras, "ir contra isso é pregar no deserto": "Logo, a menina tem que ser educada para o casamento, fatalmente, irremediavelmente, pela força das tradições, (...) dos preconceitos, (...) de tudo.”. Essa era uma realidade, ancorada em

percurso, frequentou alguma instituição escolar. No período em questão, a escolarização doméstica era uma tendência fortemente observada na educação de filhos, e principalmente de fillhas, das famílias de condições sociais favorecidas, como era o caso de Carmen Dolores. Independentemente do caminho exato trilhado, as menções nas duas citações sinalizam para uma educação atípica para uma moça de seu tempo. A referência ao fato de ter concluído os preparatórios - exames parcelados que davam acesso a cursos de nível superior -, reforça essa ideia.

Rev. Caminhos da Educação: diálogos, culturas e diversidades, Teresina, v. 2, n. 3, p. 10-37, set./dez. 2020 
padrões de gênero rigidamente estabelecidos, que compunha o "triste destino feminino" do qual a escritora entendia não ser possível à mulher escapar naquele tempo, ou, ao menos, não totalmente.

No entanto, a autora também se preocupava em apresentar situações de vida em que a mulher poderia não contar com apoio do marido para sua subsistência, o que ocorria quando a mesma era "abandonada (...), ou viúva, ou celibatária." Referindo-se, ainda, à vida de casais, apontava para o desemprego, ou problemas financeiros, como circunstâncias comuns que poderiam conduzir a dificuldades do homem no provimento da família, e à necessidade de colaboração da esposa. Todos esses cenários demandariam um outro tipo de atitude da mulher perante a vida, envolvendo seu protagonismo na busca pelo sustento, e requerendo uma formação adequada para esse fim. Considerando, então, esse quadro, Carmen Dolores entendia que "a educação da mulher tem que ser previdente, trate-se ou não do casamento", e, com esse foco, apresentava a proposta:

(...) que na educação para o casamento, que é toda de avassalamento ao marido, se enxerte prudentemente o corretivo de um preparo para qualquer eventualidade futura. Conte a mulher sentimentalmente com o homem, já que não pode prescindir do amor - e na nossa raça, o amor é o casamento; mas conte praticamente consigo mesma para o que possa advir de anormal.

E esta forma de educação requer toda uma ordem de conhecimentos que não sejam apenas frívolos. Que adianta a mulher tocar uma valsa (...) ou cantar languidamente um romance (...)? Para agradar, basta, para ajudar a viver, é muito pouco.

Aprendam elas música a fundo, e português castiço, e línguas, e a arte sólida do cozer, bordar, cozinhar, fazer doces - o que, de resto, não exclui a graça da toilette nem do sorriso.

Isto aprendido como base, deixem correr o marfim. (DOLORES, 08/04/1906, p.1, grifos da autora)

A autora acrescentava que, ao ser "obrigada a lutar pela existência, quanta coragem não insuflam todos esses elementos capazes de proporcionar o pão!...". Tais elementos, devendo compor uma educação consistente tanto no sentido intelectual quanto prático, ofereceriam à mulher possibilidades diversas de enfrentamento da situação, como ocorreu no seu caso.

No mesmo texto, seguindo na resposta à enquete publicada no jornal, após defender uma formação que possibilitasse à mulher enfrentar os desafios Rev. Caminhos da Educação: diálogos, culturas e diversidades, Teresina, v. 2, n. 3, p. 10-37, set./dez. 2020 
materiais que porventura se apresentassem em sua vida, expressava, de forma muito enfática, seu lamento indignado diante de uma realidade tão impeditiva para a mulher naquela sociedade:

Agora, quanto ao gênero de trabalho em que pode ela ganhar a vida em nossa sociedade, sem decair, eu responderei ao plebiscito de $\mathrm{O}$ Paiz, muito nitidamente e sem uma vacilação, com uma só palavra: - Nenhum.

E repito, e repetirei sempre:

- Nenhum.

Os nossos costumes, por isso mesmo que são ingênuos e se apoiam em preconceitos e tradições, não admitem a mulher que trabalha. Apresente-se ela com relativa abastança, calando os meios por que a mantém - e todos se lhe mostram pródigos de amabilidades. Mas confesse a imprudente que deve unicamente ao seu labor o pouco que tem - e todos a encaram logo com reserva e desconfiança.

'Fulana já está cozendo para fora, sabe? Já manda vender biscoitos, coitada! Já está obrigada a dar lições para viver, infeliz!...

E começa o movimento de recuo.

Assim mesmo as professoras já lograram subir um pouco na cotação social. As médicas vão impondo-se pouco a pouco ... Mas as dentistas e as advogadas estão custando a ganhar terreno. E quanto às escritoras, ai, santo nome de Jesus! que horror! Coitadinhas delas!...” (DOLORES, 08/04/1906, p.1)

Se, de acordo com a visão de Carmen Dolores, preconceitos seriam dirigidos a todas as mulheres que se lançassem na busca de seu sustento, a reprovação social teria como alvos principais aquelas que construíssem um caminho profissional apoiado em seus recursos intelectuais. Atividades remuneradas conduzidas a partir da casa como extensão dos afazeres domésticos pareciam ser mais aceitáveis, naquele cenário. Essas funções, além da associação ao espaço privado e ao gênero feminino, traziam consigo o viés do trabalho manual, socialmente inferiorizado diante da ocupação intelectual, sendo menos censuráveis quando desempenhadas pela mulher, em caso de necessidade, na medida em que reforçavam hierarquias tradicionalmente estabelecidas.

Respondendo a argumentos do professor e jornalista católico Dr. Carlos de Laet contrários ao divórcio, em discussão à época, e ao que era apontado por ele como "pedantismo feminista" responsável pela atuação da mulher diante do homem como uma "rival nas rudes competições da vida", a cronista assinalava que "para fugir aos 
pedantismos, aliás tão longe de mim", talvez fosse indicado que "me refugiasse no fundo do quintal, a lavar e engomar...”. E se dirigia a outras mulheres: “Artistas, professoras, médicas, advogadas, jornalistas! vós todas que fostes criadas fora do rude labor manual, (...) considerai que esse afastamento da tina de barrela ou do ferro quente vos condena à desqualificação do feminismo..." (DOLORES, 30/06/1907, p.1)

Sobre a condenação a que mulheres como ela estariam sujeitas, Carmem Dolores sublinhava, em outra crônica:

E se alguma rompe a rotina, trabalha, escreve, dá lições, as outras, e também os homens, todos esticam um desdenhoso beiço e murmuram, abanando gravemente com a cabeça: "Anda por aí ganhando a vida, ensinando, fazendo uns livros... É quase uma desqualificada..." (DOLORES, 04/06/1905, p.1)

Ao mesmo tempo em que ironizava o lugar de "coitadinha", ou de "desqualificada", defendia, com orgulho, seu papel na esfera pública e profissional:

De resto não me envergonho de ser jornalista - se o sou, escrevendo o que escrevo sem a mínima pretensão e jamais analisando o meu papel; e não me envergonho porque, quando a adversidade bateu à minha porta, não me perguntou se eu era mulher ou homem, (...): aconselhou-me apenas que eu usasse a faculdade que mais viva se encontrava em meu cérebro, para ganhar o meu pão e o da minha família. (DOLORES, 09/08/1908, p.1)

A referência à luta por sua subsistência e de sua família como motivação e justificativa para o exercício de sua atividade profissional no mundo das letras encontrava-se em diversas de suas crônicas. Mencionava, em várias delas, o fato de, já viúva, ter perdido o filho mais velho que havia se tornado o arrimo de sua família. Após a morte desse filho, viu-se, segundo sublinhava, compelida a buscar recursos financeiros e, com esse fim, assumir formalmente, com a remuneração devida, uma atividade que, até então, exercia apenas de forma diletante, como seria esperado de uma mulher de condição social privilegiada. ${ }^{10}$

\footnotetext{
${ }^{10}$ Essa situação explica o fato de a escritora ter iniciado a sua carreira literária de forma tardia, aos 45 anos de idade, quando publicou o primeiro livro e passou a colaborar na imprensa. É digno de nota que Carmen Dolores tenha deixado uma produção significativa e tenha conquistado tanto sucesso de público e crítica em seu tempo, apesar de sua presença na cena literária ter sido curta, por ter falecido 13 anos depois.

Rev. Caminhos da Educação: diálogos, culturas e diversidades, Teresina, v. 2, n. 3, p. 10-37, set./dez. 2020
} 
Apesar de apontar, em tom irônico, calcado em análise objetiva da realidade, que não haveria nenhuma função em que a mulher pudesse "ganhar a vida (...) sem decair" (DOLORES, 08/04/1906, p.1), Carmen Dolores enxergava gradações no preconceito da sociedade em torno do trabalho feminino. Observava maior tolerância com a remuneração obtida a partir de atividades manuais associadas ao lar, e percebia o magistério também como um caminho profissional que encontraria algum grau de aceitação social. Se, por um lado, a crítica ao trabalho intelectual atingia também a professora, por outro, sua participação já muito significativa, à época, na escolarização de crianças se mostrava como um fato que requeria consideração.

Em um trecho da revista Ilustração Brasileira, reproduzido em uma de suas crônicas, era apresentada uma compreensão muito compartilhada, então: "A única ocupação intelectual para o sexo feminino no Brasil é o magistério primário, que lhe está quase exclusivamente entregue." (DOLORES, 06/06/1909, p.1) Segundo muitos estudos têm evidenciado, a expressão, em diversos discursos da época, de representações associando a docência à suposta natureza feminina e à maternidade concorreu para a aceitação progressiva do desempenho dessa atividade por mulheres, contribuindo, por sua vez, para o processo da chamada feminização do magistério. ${ }^{11}$

Outras profissões, no entanto, sofreriam restrições sociais muito mais acentuadas, motivando fortes críticas de Carmen Dolores. Um desses campos profissionais defendidos quanto a seu exercício por mulheres, foi o direito. Uma advogada, em especial, Myrthes de Campos, foi mencionada em diversas de suas colunas, sendo denunciada a discriminação de que era alvo. Também era sublinhada a contradição entre uma legislação que permitia que moças cursassem a Faculdade de Direito, mas negava às mesmas, depois de formadas, as condições para o desempenho de sua função profissional:

A lei é engraçada, não há dúvida. Não protege absolutamente a mulher, não lhe faculta na vida uma só garantia, um só privilégio, e ainda por cima quer vedar-lhe os meios de ganhar altiva e honestamente a sua independência!

Assim também, além de engraçada, a lei é absurda e sustenta incoerências que até fazem rir. Admite por exemplo que a mulher

\footnotetext{
${ }^{11}$ Sobre debates que se desenvolveram, em inícios do século XX, em torno do tema da educação e do trabalho femininos, e do magistério em sua associação à suposta natureza feminina, tendo contado com a participação de Carmen Dolores, ver RIZZINI e SCHUELER, 2018.

Rev. Caminhos da Educação: diálogos, culturas e diversidades, Teresina, v. 2, n. 3, p. 10-37, set./dez. 2020
} 
curse a faculdade jurídica e queime as suas pestanas no estudo do direito, até obter, como qualquer homem, o grau de bacharel. (...) Chegada, porém, a esse derradeiro março, o que sucede a mulher? (...)

'Alto lá, frágil criatura! Nós brincamos contigo. Nunca fruirás o legítimo fruto do teu esforço, das tuas despesas, das tuas vigílias, do teu trabalho, porque nós, que te aceitamos na faculdade de direito, como capaz de lhe seguires o curso, nós te reconhecemos incapaz de receberes o prêmio desse curso e te negamos as qualidades legais para a profissão de advogado.'

Não é verdade, Sra. Myrtes de Campos, que as coisas se passam assim? (DOLORES, 01/ 07/1906, p.1)

Uma causa que gerou visibilidade para essa advogada, à época, parece ter contribuído para o preconceito dirigido contra si, ao mesmo tempo em que atraiu a admiração entusiasmada da cronista, explicitada em diversos de seus textos: a do divórcio. Após felicitar o Instituto dos Advogados pelo posicionamento adotado, "compreendendo a necessidade indeclinável do divórcio como lei vencedora da rotina”, Carmen Dolores conferiu destaque à atuação, nos debates da instituição, de “D. Myrthes de Campos, a jovem advogada, cuja mentalidade serena e altiva jamais se deixou assoberbar pela covarde onda de insultos com que tentaram refrear-lhe a ação feminina”. (DOLORES, 11/08/1907, p.1)

O direito ao divórcio representou uma bandeira presente com grande força na atuação de Carmen Dolores como intelectual, no cenário político-cultural da Capital da República, naquele início do século XX, quando a questão se encontrava em discussão. Em muitas de suas crônicas, analisou o tema, manifestando-se em favor de sua aprovação como lei, em um contexto de disputas que se desenrolavam, então, nos meios jurídicos e políticos. Saudou a chegada da campanha ao Senado, assim como a adesão declarada de alguns senadores, dando força à causa: "Uma mulher advoga ou escreve, na defesa da tese do divórcio: pode ser atacada; mas um senador legisla, dois senadores legislam... E agora?". Assinalava, então, que o opositor habitual era "muito menos corajoso e agressivo diante de uma cadeira senatorial do que em frente a um leve vestido feminino. (DOLORES, 15/09/1907, p.1)

Através de sua atuação jornalística semanal, reuniu argumentos, repercutiu vozes e discussões em prol da medida, levando-os até leitoras e leitores, a quem 
procurava convencer, exercendo um papel de intelectual mediadora de extrema relevância. ${ }^{12}$ Se o casamento era apresentado como o horizonte socialmente projetado para a mulher brasileira e como fator essencial na conquista de sua respeitabilidade, a autora enfatizava sua certeza de que nem sempre esse resultado era alcançado nas vidas femininas. Assim como se preocupava com a educação apropriada das moças, considerada essencial em caso de impossibilidade, ou limites do apoio masculino, demonstrava forte inquietação também com a situação jurídica e moral da mulher, em caso de separação do marido, prevista legalmente desde a instituição do casamento civil no país, com a implantação da República, mas sem a dissolução do vínculo conjugal.

Apesar da consideração da força do casamento como instituição, Carmen Dolores chamava a atenção para a imprevisibilidade da realidade e para a infelicidade que poderia se abater sobre os casais, gerando, por vezes, acontecimentos trágicos. Muitas situações eram apontadas como causas do fim do matrimônio, sendo, com frequência, impostas à esposa, como no caso de seu abandono pelo marido. Independentemente da circunstância, todas conduziriam, segundo a cronista, ao desamparo da mulher, tanto em relação a seu sustento, quanto à sua honra. Nos combates empreendidos pela escritora por meio de seus escritos, procurava contribuir para a educação da sociedade, tendo como horizonte a aceitação social do trabalho feminino e do divórcio, indicados como caminhos de enfrentamento da terrível condição a que as mulheres ficavam expostas.

Ainda que, em seus textos, sublinhasse as desvantagens evidentes enfrentadas pelas mulheres frente aos homens em caso de separação, tanto no sentido financeiro, quanto moral, apresentava o divórcio como saída para o casal infeliz. Em sua visão, o divórcio aparecia como a correção de

“(...) uma falha da lei, apresentando o único remédio possível para certos casos perdidos, em que a felicidade do homem e da mulher, e o seu futuro, e a sua dignidade, ficam exclusivamente dependentes dessa pequenina coisa, um último elo, conservado ninguém sabe por que, uma vez que tudo o mais se espedaçou nesse casal, transformado em um par de irreconciliáveis inimigos que a própria sentença judicial separou.” (DOLORES, 13/06/1909, p.2)

\footnotetext{
${ }^{12}$ Sobre a relevância do papel social exercido por intelectuais mediadores, ver GOMES e HANSEN, 2016. Rev. Caminhos da Educação: diálogos, culturas e diversidades, Teresina, v. 2, n. 3, p. 10-37, set./dez. 2020
} 
Segundo mostrava a leitores e leitoras, a situação da mulher desquitada era de extrema marginalização, "trancadas diante dela todas as portas do futuro, sem liberdade para melhorar de sorte, sem recursos, sem o apoio social (...)". No mesmo escrito em que apresentava esse diagnóstico, publicava a "resposta odiosa" dada por um "frio advogado", nos debates no Instituto dos Advogados, à pergunta sobre como resolver essa situação em que tantas mulheres se encontravam: “ - Ora, como nos naufrágios, ninguém pensa nos 'cadáveres'... Eles ao fundo do mar!". Questionando a crueldade do comentário, mostrava sua indignação: "Então, doutor, a divorciada, muitas vezes na flor dos anos, quase criança, vítima incauta - essa divorciada tem de considerar-se para todo o sempre, e ainda viva e cheia de aspirações, um 'cadáver'?" (DOLORES, 09/06/1907, p.1)

$\mathrm{Na}$ visão da escritora, somente com uma nova lei, as mulheres poderiam se ver liberadas dessa condição perversa, denunciada em muitos de seus escritos. Em uma matéria em sua homenagem publicada em O Paiz, no dia seguinte à sua morte, foram reproduzidas respostas suas a um questionário, em meio às quais aparece mais uma vez a referência ao tema que tanto a mobilizou, ao lado de outros a que a vida feminina costumava ser fortemente associada, abordados sem fantasia e nem idealização, de forma realista, como era comum em suas crônicas: "O amor é a luz da existência. $\mathrm{O}$ casamento representa uma experiência bem ou mal sucedida. A maternidade é uma aliança de doçuras e amarguras e o divórcio uma necessidade." (Carmen Dolores. Vida Social. O Paiz, 17/08/1910, p. 3).

\section{Combatendo pelo "progresso feminista"}

Assim como contemporâneos haviam reconhecido em seu tempo, inúmeros estudos produzidos nas últimas décadas também têm ressaltado o feminismo de Carmen Dolores, sendo essa marca percebida de formas diversas. Rachel Soihet e Flávia Esteves, por exemplo, assinalam o viés contraditório de que se revestiria sua face feminista, destacando que, apesar das "incoerências, incompatibilidades internas 
da própria Carmen", a escritora expressaria “uma significativa consciência de gênero". (2008, p. 155; 163)

Nas crônicas analisadas, foram, realmente, observadas manifestações distintas da escritora sobre o tema, o que poderia ser compreendido na chave da "contradição". $\mathrm{Na}$ linha do que sugere Bourdieu, cabe também considerar que nenhum sujeito apresenta uma identidade coesa, ou constante, e nenhuma vida deve ser considerada como "um conjunto coerente e orientado". (BOURDIEU, 2005, p. 184) Olhar desse modo para um indivíduo e sua trajetória no passado, tratando esta última em um sentido linear, como se fosse possível uma definição prévia para um percurso e como se este fosse pontuado por "certezas", muitas delas afirmadas a posteriori, nos levaria ao que o autor apresenta como a armadilha da "ilusão biográfica". (Ibidem) Esse é um caminho que deve ser evitado, por conduzir a uma perda significativa na interpretação sobre esse indivíduo e sobre a riqueza dinâmica da vida, com seus acasos, suas imprevisibilidades, e com os limites impostos pela historicidade e pelas condições sociais específicas experimentadas por qualquer sujeito em sua vivência particular. Pautar-se em uma compreensão fechada sobre o que constituiria a identidade feminista, na análise sobre figuras que atuaram em favor de direitos das mulheres naquela virada do século XIX para o XX, como foi o caso de Carmen Dolores, poderia contribuir, assim, para uma visão pouco ancorada na complexidade da realidade social, com o risco de se incorrer no equívoco do anacronismo.

Em uma de suas colunas, ao enfrentar corajosamente Carlos de Laet, respondendo a críticas desqualificadoras dirigidas por este intelectual católico a posicionamentos seus em torno do tema da religião, a cronista reafirmava a "firme impassibilidade das minhas opiniões". Em seguida, assinalava:

Nem por isso me considero feminista, livre pensadora ou coisa que o valha. Histórias! Tenho pelo contrário a consciência de ser uma boa mãe de família - assaz o hei provado - e um espírito profundamente temente a Deus, diante de cuja onipotência me curvo, sempre reverente, como a mais convicta das católicas.

A ironia habitual da escritora, já observada em outras passagens, também se manifestava nessa declaração, negando sua identidade como feminista, reforçando, em direção contrária, a de mãe - referência quase ausente em seus textos -, recusando Rev. Caminhos da Educação: diálogos, culturas e diversidades, Teresina, v. 2, n. 3, p. 10-37, set./dez. 2020 
o livre pensar e assumindo-se como católica submetida à autoridade divina onipotente. Apesar de identificar-se como católica, enfatizava, por outro lado, no mesmo texto, e em outro tom, parecendo estimular leitores a relativizar sua afirmação anterior, sua crítica radical aos "abusos do clero, (...) suas injustiças e despotismo, falsidades" apresentados "como a fiel expressão da vontade de Deus" (DOLORES, 09/08/1908, p.1)

Quanto ao feminismo, sua relação com o movimento foi uma questão que mobilizou fortemente suas reflexões, e em que importantes nuances merecem ser destacadas, indicando muito mais aproximações que distanciamento. Nas crônicas em que se dedicou ao tema, é possível perceber críticas dirigidas ao feminismo e a feministas, o que também se observa na seguinte resposta a um questionário a ela dirigido:

Só compreendo o feminismo como meio de garantir à mulher $\mathrm{o}$ direito de concorrer ao trabalho, igual ao homem, quando precisa lutar pela vida; mas acho inútil a sua incorporação à política, forma apenas grotesca de um exibicionismo sem necessidade, que fere preconceitos sem vantagem, senão para a vaidade feminina. (Carmen Dolores. Vida Social. O Paiz, 17/08/1910, p.3)

Nesse enunciado, Carmen Dolores mostrava sua desconfiança em relação à aproximação do feminismo com a política formal, seguindo na mesma direção de outras manifestações suas, de rejeição da vida política tal como se apresentava naqueles primeiros tempos republicanos, e assinalando, ainda, sua desaprovação em relação à vaidade e ao exibicionismo como motivações possíveis para feministas buscarem esse caminho. Em outros escritos, por outro lado, elogiava a atuação de feministas que seguiam essa trilha do envolvimento com a política, como o fez dirigindo-se a Leolinda Daltro, destacada como "grande patriota brasileira", ainda que se diferenciasse da mesma. Sinalizava, assim, para diferentes formas de inserção das feministas na luta política mais ampla, reconhecendo seu mérito em situações específicas.

Em diversas crônicas, demonstrava sua admiração por mulheres envolvidas na cena cultural e artística e nas lutas feministas na Europa, conferindo destaque à aceitação e ao prestígio que conheceram em suas sociedades, de forma tão distinta da Rev. Caminhos da Educação: diálogos, culturas e diversidades, Teresina, v. 2, n. 3, p. 10-37, set./dez. 2020 
situação vivida em nosso país. Em diálogo com o correspondente de O Paiz na capital francesa, este assinalava que a "causa internacional do feminismo vai-se desenvolvendo imenso na França”, mas, em sua opinião, muito faltaria para esse país “conseguir os maravilhosos resultados do norte da Europa (...)" Questionando a visão de seu colega jornalista e refletindo acerca da "causa internacional do feminismo ou direito das mulheres às garantias do trabalho", a escritora o desafiava:

Venha o Sr. Xavier de Carvalho ao Rio de Janeiro, estude aqui as nossas ideias retrógradas nesse sentido, vá depois aos Estados, estabeleça a comparação entre a maneira de encarar a mulher aqui e na Europa, e ficará tendo a prova do admirável desenvolvimento que, apesar de tudo, seja embora o norte europeu mais favorecido pela triunfante evolução social, ainda faz da luminosa Gália o centro da mais bela e nobre independência do pensar e do sentir. (DOLORES, 06/06/09, p.1)

Em outro texto, ainda que enfatizasse a profunda diferença entre a maneira como eram observadas as feministas em inúmeros países - focalizando, no caso, os Estados Unidos - e no Brasil, onde a regra era o preconceito manifestado contra mulheres supostamente "masculinizadas", a cronista mostrava valorizar o caminho percorrido pelo movimento também entre nós, apesar das fortes barreiras interpostas a seu desenvolvimento. Partindo dessa ideia, censurava aqueles homens que resistiam contra mudanças relativas ao lugar da mulher na sociedade:

E agora que o feminismo caminha em nosso meio a passos de gigante, pela força da necessidade que impele a mulher a aproveitar suas aptidões em socorro da vida material, cada vez mais árdua não seria conveniente apararmos as penas de galo de alguns desses pobres de espírito que se fingem de brilhantes pavões e cujos tacanhos pareceres vão sempre dando para baixo nas mulheres que lutam pelo pão ou pela glória, trabalham, escrevem, ensinam, fazem arte, são pintoras, escultoras, médicas, advogadas, jornalistas? Penso que sim. (DOLORES, 21/04/07, p.1)

Seguindo nessa direção, Carmen Dolores confrontou-se diretamente com os opositores do movimento, denunciando a arma do "ridículo - triste arma da covardia!” de que os “antifeministas”, tentariam lançar mão para expor as mulheres, como quando ofereciam "belos vestidos" às feministas na intenção de calar o barulho de suas vozes. (DOLORES, 11/08/07, p.1) Ao defender essas "lutadoras" mobilizadas em favor do direito das mulheres ao enfrentamento da vida contando 
com os próprios recursos, a escritora sinalizava para a sua adesão ao movimento, ou, ao menos, para sua aproximação em relação a diversos pontos defendidos pelo mesmo.

Quando, em uma passagem citada anteriormente, a autora criticava a expressão do feminismo como exibicionismo, que terminaria por ferir "preconceitos sem vantagem", sugeria identificar-se com um sentido prático dessa luta. Na perspectiva adotada, o interesse parecia localizar-se na defesa do direito de mulheres serem educadas de forma consistente e de ocuparem postos de trabalho para seu sustento, tendo como foco a obtenção de ganhos objetivos para as vidas femininas. Para essa meta ser atingida, ainda que com muitos limites e resistências, um caminho essencial parecia se localizar na negociação com a realidade vigente e com os valores tradicionalmente compartilhados pela sociedade.

Essa era a forma, por exemplo, como Carmen Dolores lidava com o tema do casamento, apresentando-o como o horizonte mirado por mulheres e famílias. Partindo desse entendimento declarado, defendia a preparação previdente da mulher e o apoio a ela, nas situações em que esse ideal não fosse atingido, ou fosse perdido. Talvez, ao dialogar com padrões socialmente hegemônicos, seus questionamentos e argumentos pudessem encontrar menor reação e maior aceitação na sociedade e sua ação educativa pudesse conduzir a um resultado mais eficaz. Longe de se mostrar presente apenas nos posicionamentos dessa escritora, esse tipo de postura também se evidenciava nas ações de outras mulheres que lutaram, naqueles primeiros tempos republicanos, em prol de conquistas femininas e feministas, adotando uma perspectiva tática. ${ }^{13}$

Em uma crônica focalizando a atuação de mulheres "laboriosas", uma francesa, Mme. Curie, que havia assumido a cadeira antes ocupada pelo marido na Sorbonne, e duas brasileiras, "nomeadas para o cargo de $2^{a}$ oficial do Museu Paraense, dirigido pelo sábio naturalista Dr. Goeldi”, a escritora destacava o êxito das três: “Assim, pois, em Paris e num dos mais adiantados Estados do norte brasileiro,

\footnotetext{
${ }^{13}$ Rachel Soihet, em estudo sobre a líder feminista Bertha Lutz, opera com a noção de "feminismo tático", com que dialogamos no presente trabalho, na análise da atuação de Carmen Dolores. Ver SOIHET, 2006. Em estudo anterior sobre Júlia Lopes de Almeida, também apontamos para o sentido tático das lições de conciliação dessa escritora que cumpriu importante função educativa. Ver MAGALDI, 2007, capítulo 1. Rev. Caminhos da Educação: diálogos, culturas e diversidades, Teresina, v. 2, n. 3, p. 10-37, set./dez. 2020
} 
mulheres são distinguidas por uma escolha de seleção que a rotina, outrora, não consentiria que recaísse senão sobre homens." Ao considerar o processo dinâmico em curso, envolvendo pesadas barreiras, mas também ganhos, entendia ser importante exaltar a realização daquelas mulheres: "É um passo à frente na senda do progresso feminista.” (DOLORES, 06/01/1907, p. 1)

Por meio de sua pena combativa e atuante até dois dias antes de sua morte, em que se manifestava uma intenção de educar leitoras, leitores e a sociedade em termos mais amplos, Carmen Dolores forneceu uma importante contribuição para que muitos outros passos fossem dados na direção da afirmação dos direitos das mulheres brasileiras, luta que ainda se mostra viva, potente e crucial em nosso presente, incorporando novos desafios e protagonismos.

\section{Referências}

ALMEIDA, Júlia Lopes. Carmen Dolores. O Paiæ. Rio de Janeiro, 23/08/1910, p.1.

AMADO, Gilberto. A Semana. O Paiz. Rio de Janeiro, 21/08/1910, p.1.

BOURDIEU, Pierre. A ilusão biográfica In FERREIRA, Marietta de Moraes, AMADO, Janaína (Org.). Usos e abusos da história oral. 6 ed. Rio de Janeiro: Editora FGV, 2005.

CERTEAU, Michel de. A invenção do cotidiano: artes de fazer. 2 ed. Petrópolis, RJ: Vozes, 1994.

CHALHOUB, Sidney, NEVES, Margarida de Souza e PEREIRA, Leonardo Affonso de M. (Org.). História em cousas miúdas. Campinas: Editora da UNICAMP, 2005.

DOLORES, Carmen. A Semana. O Paiz: Rio de Janeiro. (08/01/1905 a 14/08/1910)

GOMES, Ângela de Castro, HANSEN, Patrícia (Org.). Intelectuais mediadores: práticas culturais e ação política. Rio de Janeiro: Civilização Brasileira, 2016.

GRIECO, Agripino. Carmen Dolores. A Imprensa. Rio de Janeiro, 18/08/1910.

HELLMANN, Risolete Maria. Carmen Dolores, escritora e cronista: uma intelectual feminista da Belle Époque. Tese (Doutorado em Literatura). Universidade Federal de Santa Catarina. Florianópolis, 2015.

MAGALDI, Ana Maria B. M. Lições de casa: discursos pedagógicos destinados à família no Brasil. Belo Horizonte: Argvmentvm, 2007.

O PAIZ. Carmen Dolores. Rio de Janeiro, 17/08/1910, p.3.

PORTO-CARRERO, Júlio. Carmen Dolores. A Imprensa. Rio de Janeiro, 19/08/1910, p.3.

Rev. Caminhos da Educação: diálogos, culturas e diversidades, Teresina, v. 2, n. 3, p. 10-37, set./dez. 2020 
RIZZINI, Irma, SCHUELER, Alessandra F. M. Entre o mundo da casa e o espaço público: um plebiscito sobre a educação da mulher (Rio de Janeiro, 1906). Revista de bistória e historiografia da educação. Curitiba, v.2, n.4, janeiro/abril 2018.

SEVCENKO, Nicolau. Literatura como missão: tensões sociais e criação cultural na Primeira República. São Paulo: Brasiliense, 1999.

SOIHET, Rachel. Comparando escritos: Júlia Lopes de Almeida e Carmen Dolores. Revista do Instituto Histórico e Geográfico Brasileiro. Rio de Janeiro. v. 423, 2004. O feminismo tático de Bertha Lutz. Florianópolis: Ed. Mulheres; Santa Cruz do Sul: EDUNISC, 2006.

ESTEVES, Flávia C. Carmen Dolores: as contradições de uma literata da virada do século In LÔBO, Yolanda e FARIA, Lia (orgs.) Vozes femininas do Império e da República. Rio de Janeiro: Quartet: FAPERJ, 2008.

RECEBIDO: 01/07/2020

RECIBIDO: 01/07/2020

APROVADO: $10 / 08 / 2020$

APROBADO: $10 / 08 / 2020$

RECEIVED:01/07/2020

APPROVED: $10 / 08 / 2020$

Rev. Caminhos da Educação: diálogos, culturas e diversidades, Teresina, v. 2, n. 3, p. 10-37, 